\title{
SUMMARY AND COMPARISON OF METHODS TO CALCULATE SOLAR HEAT GAIN
}

\author{
John L. Wright, Ph.D., P.Eng. \\ Member ASHRAE
}

\section{ABSTRACT}

Methods used to calculate the solar gain of windows (including center-glass, edge glass, and frame) are examined and compared. Particular attention is devoted to the public-domain computer programs VISION3 and WINDOW 4.1. Calculated results are presented to quantify the sensitivity of solar heat gain with respect to a wide range of glazing system design parameters and operating conditions. Details concerning solar optical properties and heat transfer mechanisms are examined and discussed. When possible, comments are made concerning the development of solar gain measurement procedures. Solar gain is most sensitive to the solar optical properties of the glazings-the most important property being the transmittance of the outdoor glazing. Variables that directly affect heat transfer rates (e.g., fill gas type, convective heat transfer coefficients) have a significantly smaller effect.

\section{INTRODUCTION}

\section{Background}

Two public-domain window analysis programs, VISION and WINDOW, are widely used in North America. WINDOW was produced by a U.S. laboratory and VISION was written by the author of this paper. Both programs have been released in several versions. In general, the information included here pertains to the most recent versions of eachWINDOW 4.1 and VISION3.

The best source of information regarding the models used in WINDOW is a report prepared for the U.S. Department of Energy (DOE) by Finlayson et al. (1993). Other sources include Arasteh et al. (1989) and Appendix A of the WINDOW 4.0 program description manual (LBL 1992). These three documents pertain specifically to WINDOW 4.0 , but material included with WINDOW 4.1 states that "no internal program calculations have changed in version 4.1." The VISION3 models are documented in the VISION3reference manual (Wright and Sullivan 1992).

This paper examines window solar heat gain-how it is calculated and what affects it. Window solar heat gain is quantified by the solar heat gain coefficient (SHGC), which is simply the portion of radiant solar energy incident on a window that reaches the conditioned space of the building, thus reducing the heating load or adding to the cooling load. It is customary to analyze a window by examining each of three areas: (1) the center-glass area, $A_{\text {cg }}$ (i.e., the glazed area more than $2.5 \mathrm{in} .(63.5 \mathrm{~mm})$ from any sight line); (2) the edge-glass area, $A_{e g}$; and (3) the frame area, $A_{f r}{ }^{1} A_{f r}$ is the area, projected to the plane of the wall, of the rough opening minus installation clearance and the view area (view area = $A_{c g}+A_{e g}$ ). SHGC values can be found for each of the three component areas. These are $\mathrm{SHGC}_{c g}, \mathrm{SHGC}_{e g}$ and $\mathrm{SHGC}_{f r}$, respectively. The component SHGC values can be areaweighted to give the total window SHGC:

$$
\mathrm{SHGC}=\frac{A_{c g} \cdot \mathrm{SHGC}_{c g}+A_{e g} \cdot \mathrm{SHGC}_{e g}+A_{f r} \cdot \mathrm{SHGC}_{f r}}{A_{c g}+A_{e g}+A_{f r}} .
$$

VISION3 deals only with the center-glass portion of the window. WINDOW 4.1 can be used to determine the SHGC of an entire window but this program actively models only the center-glass area while drawing results from other sources that describe the performance of the edge-glass and frame sections. On this basis, it can be said that VISION3 and WINDOW 4.1 perform similar calculations. They can both be used to perform solar optical and heat transfer calculations to arrive at center-glass SHGC values. These programs are both limited to dealing with planar glazings with specular solar optical properties. Components that cannot be dealt with include nonspecular items such as frost glass, fiberglass-reinforced panels and shades, or curved items such as bubble skylights.

VISION and WINDOW both take advantage of the fact that there is no appreciable overlap between the band of solar wavelengths below about $3 \mu \mathrm{m}$ and the band of longer wavelength radiation in which heat transfer takes place. In this sense both programs employ a two-band analysis that leads naturally to a two-step simulation process. First, an optical analysis determines how much of the solar radiation is reflected from the glazing system to the outdoor environment, how much is absorbed at each of the glazings, and how much is transmitted directly to the indoor space. Second, a heat

${ }^{1}$ The additional complexity of considering meeting rails and differences in head/sill detail, etc., is not included in this study.

John L. Wright is a manager and a research engineer at the Advanced Glazing System Laboratory in the Department of Mechanical Engineering at the University of Waterloo, Waterloo, ON, Canada. 
transfer analysis is used to impose an energy balance on each glazing. The net heat transfer from any glazing must be equal to the amount of absorbed solar radiation.

The solar optical calculation can be completed without any information regarding glazing temperatures or heat transfer. The only information from the solar optical step needed in the heat transfer step is the amount of solar radiation absorbed at each glazing. These two steps yield the temperature profile and the rate of heat transfer at each glazing or interpane gap, which can then be used to determine indices of merit such as the center-glass U-factor and $\mathrm{SHGC}_{c g}$.

WINDOW 4.1 offers the option of using a multiband solar optical model. Reflected, absorbed, and transmitted amounts of solar radiation can be estimated with a wavelength-by-wavelength calculation that can use any solar spectral irradiance function the user supplies. The ASTM E891-87 solar spectrum (air mass 1.5) is provided as the default. This multiband calculation will make a difference when two or more spectrally selective glazings are used together. No difference results when it is applied to a single glazing. All glazings are spectrally selective to some degree. The solar transmittance curves of many high-transmittance glazings rise to a peak near the visible wavelength band and drop to zero again at the upper extreme of the solar band. This characteristic occurs naturally in glass and by design in products with a low-e coating, but does not apply to many tinted and reflective products.

Examples of glazing combinations can be cited to show that solar transmittance and $\mathrm{SHGC}_{c g}$ results from the multiband model will not be higher or lower, as a rule, than the corresponding quantities calculated with a single-band model.

\section{Objective}

The goal of this study was to examine the methods used to calculate solar heat gain for windows, including a comparison of calculations used in VISION3 and WINDOW 4.1. In addition, an effort was made to quantify the importance of various parameters that govern solar gain in order to assist in the development of solar gain measurement procedures.

\section{Center-Glass Solar Heat Gain}

The solar heat gain from a glazing system consists of two components:

1. solar radiation passed through the window and absorbed indoors and

2. solar radiation absorbed within the glazing system and redirected to the indoor space by heat transfer.

The first of these two quantities is determined by the solar optical calculation. In residential windows it is usually the larger component because these windows are designed to provide good visible transmittance, which customarily results in relatively high solar transmittance as well. In con- trast, bronze glass, which is used widely for commercial applications in North America, is highly absorbing.

The second component of solar gain must be found using both the solar optical analysis and the heat transfer analysis. The amount of solar radiation absorbed at an individual glazing is determined by the optical calculation. A portion of this energy ends up going to the indoor space. The size of this "inward-flowing fraction" depends on how the thermal resistance of the glazing system is distributed from the indoor side to the outdoor side (see Equations 56 through 60 of Wright and Sullivan [1992] or Equation 5.2B of Finlayson et al. [1993]). Therefore, the heat transfer analysis must be complete, yielding the required values of thermal resistance at each step through the glazing system, before $\mathrm{SHGC}_{c g}$ can be quantified.

It can be seen how glazing systems can be divided into two broad categories. The accurate calculation of solar gain for glazing systems with high solar transmittance will rely more heavily on the solar optical model than on the heat transfer model. The amount of energy absorbed and redirected will constitute a small adjustment in relation to the energy that is directly transmitted. In contrast, some glazing systems do not transmit solar radiation well because of the presence of tinted glass or highly absorbing coatings. In this case, a more significant portion of the solar gain will result from absorbed and redirected solar energy, making it important to use an accurate heat transfer model.

It is easy to recognize the dominant mechanism by which a glazing system supplies solar gain. If the solar gain results primarily from direct transmission, $\mathrm{SHGC}_{c g}$ will be only slightly greater than the solar transmittance, $\tau_{s}$. However, if absorption/redirection contributes heavily to the solar gain, $\mathrm{SHGC}_{c g}$ will be significantly greater than $\tau_{s}$. These two cases are illustrated by the two VISION3 graphic analysis summaries shown in Figures 1 and 2. The conventional single glazing shown in Figure 1 delivers almost all of its solar gain by direct transmission $\left(\mathrm{SHGC}_{c g}=0.86, \tau_{s}=\right.$ 0.84). The double-glazed system shown in Figure 2 includes a heavily tinted glazing on the indoor side. This glazing strongly reduces the direct transmission of solar energy but absorbs a significant amount, almost all of which is redirected to the indoor space $\left(\mathrm{SHGC}_{c g}=0.62, \tau_{s}=0.27\right.$ ).

\section{Solar Gain Through Frame and Dividers}

Until recently, the accepted method to calculate solar gain through a complete window was to apply the $\mathrm{SHGC}_{c g}$ value over the entire view area and to neglect any solar gain that occurs through the frame. In this case, Equation 1 becomes

$$
\mathrm{SHGC}=\frac{\left(A_{c g}+A_{e g}\right) \cdot \mathrm{SHGC}_{c g}+A_{f r} \cdot 0}{A_{c g}+A_{e g}+A_{f r}} .
$$

However, Carpenter and Baker (1992) have developed a method to estimate $\mathrm{SHGC}_{f r}$ by calculating frame solar heat 


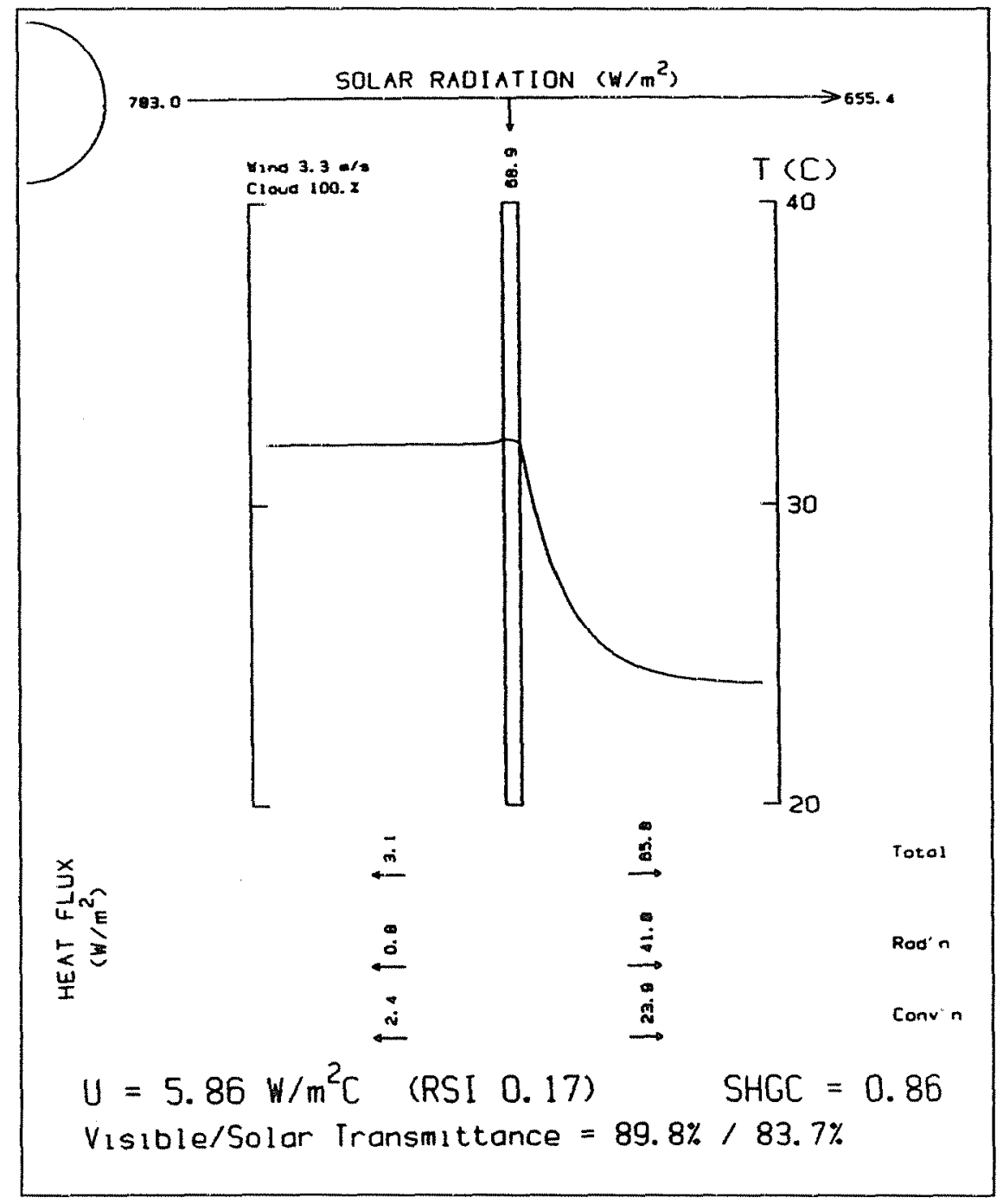

Figure 1 VISION3 graphic analysis summary-conventional single.glazed. the vertical faces of the frame surface. The presence of solar radiation at $45 \mathrm{de-}$ grees off-normal was treated by applying source terms equally along all exposed (i.e., unshaded vertical or horizontal) faces of the frame. Additional steps were taken to apply the appropriate source terms to the indoor frame surfaces exposed to off-normal solar radiation. The solar absorptance of the frame surfaces was fixed at $\alpha_{f r}^{s}=0.9$.

Carpenter and Baker concluded that $\mathrm{SHGC}_{f r} \cong 0.02$ for wood and vinyl frames and $\mathrm{SHGC}_{f r} \cong 0.14$ for thermally unbroken aluminum frames on the basis of simulations run with solar radiation incident normal to the window. Simulations with solar radiation incident at 45 degrees off-normal showed frame solar heat gains about $50 \%$ higher, but it was also pointed out that shading of the glazed area by the frame was not accounted for so "this increase may be overstated, as the frame at non-normal incidence will shade the glass, thereby reducing the solar heat gain into the room." They showed that the solar gain through the frame increases the SHGC by much less than 0.01 for wood/vinyl frames and by 0.02 to 0.03 for windows with thermally unbroken aluminum frames.

A calculation to estimate the frame solar heat gain has also been incorporated into WINDOW 4.1 (see Finlayson et al. 1993). A discussion of this apgain values for a variety of frame types using a two-dimensional (2-D) finite-difference computer program (EEL 1989). This program can model conduction heat transfer through a wide variety of cross sections. It was developed specifically for window frame simulation and models window frame and edge-glass heat transfer by dividing the construction into many rectangular elements. Energy-source terms representing amounts of absorbed solar radiation can be manually applied along the surfaces of elements where boundary conditions are imposed. Pairs of simulations were run with and without solar radiation to determine the portion of the solar radiation incident on the frame that could be treated as solar gain.

Two sets of simulations were run in order to examine the effect of off-normal solar radiation. Solar radiation was readily modeled at normal incidence and at 45 degrees offnormal because of the rectangular nature of the frame elements. The simulations accounted for solar radiation at normal incidence by including energy-source terms along only proach, along with the appropriate equations, ${ }^{2}$ can also be found in Carpenter and Baker (1992). When a frame is specified, it is necessary to provide the solar absorptivity of the frame, $\alpha_{f r}^{s}$. This is used to calculate the amount of absorbed solar radiation. The ratio between the outdoor-side convective heat transfer coefficient, $h_{c o}$, and the indoor/outdoor frame U-factor, $U_{f r}$, is taken as the inward-flowing fraction of absorbed solar radiation. This is similar to the way the inward-flowing fractions are calculated for individual glazings in glazing systems.

$$
\mathrm{SHGC}_{f r}=\alpha_{f r}^{s} \cdot \frac{U_{f r}}{h_{c o}} .
$$

Results generated using this approach contradict conclusions made by Carpenter and Baker. WINDOW 4.1 was used to model a conventional double-glazed window with various

\footnotetext{
${ }^{2}$ The equation given in this reference should be $\mathrm{SHGC}_{f r}=\alpha_{f r}\left(U_{f r}\right.$ $h_{o}$ ) instead of $\mathrm{SHGC}_{f r}=\alpha_{f r} \times U_{f r} /\left(U_{f r}+h_{o}\right)$.
} 


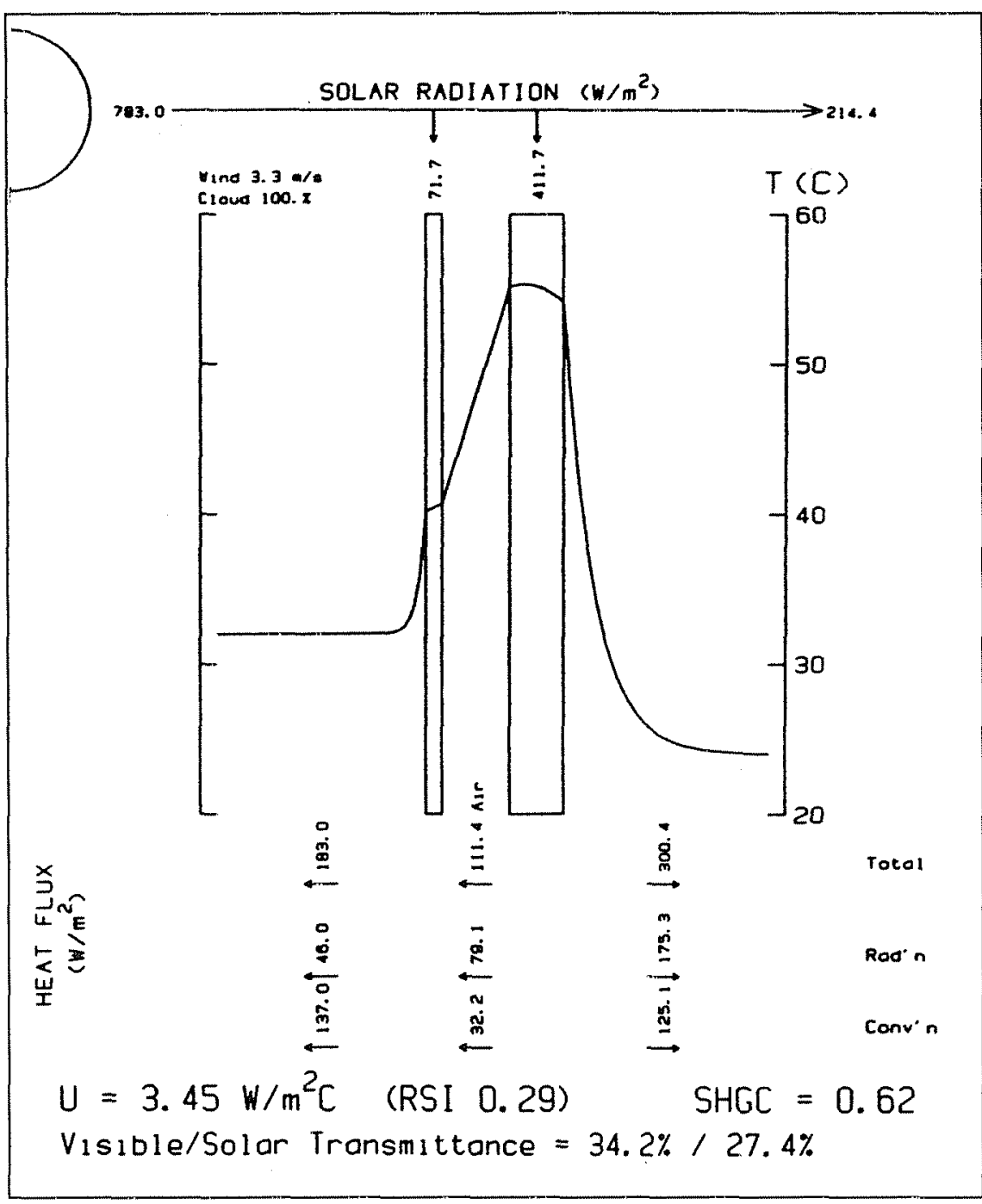

Figure 2 VISION3 graphic analysis summary-double-glazed with tinted indoor-side glazing.

frames under the ASHRAE summer design condition. The window type was "picture" and the size was ASHRAE residential $(1.22 \mathrm{~m}$ by $0.91 \mathrm{~m})$. When a wood frame was simulated using $\alpha_{f r}^{s}=0.01$ and $\alpha_{f r}^{s}=0.9$, the SHGC increased from 0.58 to 0.61 . This increase of 0.03 is much greater than the very small increase predicted by Carpenter and Baker. When WINDOW 4.1 was used to model a thermally unbroken aluminum frame with the same change in $\alpha_{f r}^{s}, \mathrm{SHGC}_{f r}$ changed from 0.62 to 0.74 . This increase of 0.12 is much greater than the increase of 0.02 to 0.03 that Carpenter and Baker suggest will occur. The same discrepancies were found using a double-glazed low-e glazing system instead.

There are several reasons why these two methods give such different results. First, Equation 3, used by WINDOW 4.1 , is only valid if the exposed surface of the frame is isothermal. This assumption is probably not unreasonable for an aluminum frame. A frame with higher thermal resistance is less likely to have an isothermal surface but it will also have a much lower solar gain, allowing for a much less sophisticated calculation. Furthermore, this method cannot allow for a nonuniform distribution of insolation over the frame surface or differences in the environment to which various parts of the frame are exposed. Second, the heat transfer coefficient shown in the denominator of Equation 3 is the outdoor convective heat transfer coefficient. Radiant heat transfer has been neglected. This is equivalent to assuming that the frame is highly reflective to longwave radiation (i.e., wavelengths greater than $3 \mu \mathrm{m}$ ). This is unlikely - especially if the frame is painted, coated, oxidized, anodized, or dirty. If the frame is not reflective to longwave radiation, it would be more accurate to use the outdoor film coefficient that also accounts for radiant heat transfer, $h_{o}$. Under the ASHRAE summer condition, $h_{o}$ is greater than $h_{c o}$ by about $30 \%$ (based on the center-glass calculation, $h_{f o} \approx 16.8 \mathrm{~W} / \mathrm{m}^{2}{ }^{\circ} \mathrm{C}$ and $h_{o}$ $\approx 22.2 \mathrm{~W} / \mathrm{m}^{2} \cdot{ }^{\circ} \mathrm{C}$ ). If $h_{o}$ were used in place of $h_{c o}$ in Equation 3, as shown in Equation 4, the resulting $\mathrm{SHGC}_{f r}$ values would be reduced accordingly-by about $30 \%$.

$$
\mathrm{SHGC}_{f r}=\alpha_{f r}^{s}, \frac{U_{f r}}{h_{o}}
$$

Third, the 2-D simulations run by Carpenter and Baker incorporated an outdoor film coefficient of $h_{o}=34.5 \mathrm{~W} /$

$\mathrm{m}^{2} \cdot{ }^{\circ} \mathrm{C}$. The WINDOW 4.1 results were generated using the ASHRAE summer design condition, which entails an outdoor film coefficient of $h_{o} \approx 22.2 \mathrm{~W} / \mathrm{m}^{2} .{ }^{\circ} \mathrm{C}$. If $h_{o} \approx 34.5 \mathrm{~W} /$ $\mathrm{m}^{2} \cdot{ }^{\circ} \mathrm{C}$ were used in Equation 4 instead of $h_{c o} \approx 16.8 \mathrm{~W} /$ $\mathrm{m}^{2} \cdot{ }^{\circ} \mathrm{C}$, the resulting SHGC $_{f r}$ values calculated by WINDOW 4.1 would be reduced by about $50 \%$.

Fourth, the frame U-factor, $U_{f r}$, shown in Equations 3 and 4 , is based on the projected frame area, $A_{f r}$. However, the heat transfer coefficients, $h_{c o}$ and $h_{o}$, that appear in the same equations are based on outdoor surface area, $A_{\text {surf }}$. This point can easily be emphasized by writing two expressions for nighttime heat transfer through the frame:

$$
U_{f r} A_{f r}\left(T_{i}-T_{o}\right)=h_{o} A_{\text {surf }}\left(T_{\text {surf }}-T_{o}\right)
$$

where

$T_{i}, T_{o}=$ indoor and outdoor temperatures, respectively; and $T_{\text {surf }}=$ outdoor frame surface temperature. 
If $h_{o}$ is to be used correctly, it must be multiplied by the ratio of frame surface to projected area. Now the expression for $\mathrm{SHGC}_{f r}$ becomes

$$
\mathrm{SHGC}_{f r}=\alpha_{f r}^{s} \cdot \frac{U_{f r}}{\frac{A_{s u r f}}{A_{f r}} h_{o}} .
$$

It is common for $A_{\text {surf }}$ to be about two times $A_{f r}$. $A_{\text {surf }} / A_{f r}$ can never be less than unity. If this factor had been included in the calculations of WINDOW 4.1, the resulting SHGC $_{f r}$ values would have been approximately halved.

At first glance the $\mathrm{SHGC}_{f r}$ values calculated by Carpenter and Baker appeared to disagree with WINDOW 4.1 results by a factor of four or more. However, the combined effect of the points listed above brings the two sets of results into much closer agreement.

Equations 3, 4, and 6 highlight the fact that $\mathrm{SHGC}_{f r}$ will be sensitive to $h_{c o}$ and $\alpha_{f r}^{s}$. This will be true for all frames but will only be evident when $\mathrm{SHGC}_{f}$ is so large that it cannot be neglected. Therefore, unless $\mathrm{SHGC}_{f r}$ itself is being examined, scatter in the solar gain test results can be reduced if glazing systems are not installed in thermally unbroken aluminum frames and if the frames have surfaces that reflect solar radiation well (e.g., white paint).

Carpenter and Baker also examined solar heat gain in the edge-glass area and concluded that the difference between $\mathrm{SHGC}_{c g}$ and $\mathrm{SHGC}_{e g}$ can be neglected. In the areas near window dividers it is expected that $\mathrm{SHGC}_{c g}$ can also be applied and that the overriding effect at dividers is the blockage of direct solar gain by the divider itself. However, if more accuracy is desired, it is possible to estimate divider solar heat gain in the same way that $\mathrm{SHGC}_{f r}$ is assessed.

In summary, Carpenter and Baker's study indicates that when reasonably well-insulated frames are used (e.g., wood/ vinyl or better) the solar gain through the frame can be neglected as expressed in Equation 2. They also show that it is valid to apply the $\mathrm{SHGC}_{c g}$ over both the center-glass and edge-glass areas (i.e., the view area) in the conventional manner.

\section{SOLAR OPTICS}

\section{Converting Glazing Properties to Glazing System Properties}

The solar optical properties of each glazing must be known before the solar optical properties of the entire glazing system can be determined. Three pieces of data are needed to fully specify the optical properties of a glazing. VISION and WINDOW both use the reflectance for solar radiation incident from the outdoor side, $\rho_{f}$; the reflectance for solar radiation incident from the indoor side, $\rho_{b}$; and the transmittance of the glazing to solar radiation, $\tau_{s^{*}}$ These data can easily be used to determine the two absorptance values of a glazing for radiation incident from either the outdoor or the indoor side, $\alpha_{o}$ or $\alpha_{i}$, since incident radiation can only be reflected, transmitted, or absorbed. That is,

$$
\rho_{f}+\tau_{s}+\alpha_{f}=1
$$

and

$$
\rho_{b}+\tau_{s}+\alpha_{b}=1
$$

The outdoor-side and indoor-side transmittance values of a glazing (with respect to the same radiation) must be equal in order to satisfy the second law of thermodynamics. Therefore, the transmittance values shown in Equations 7 and 8 carry no indoor/outdoor subscript.

VISION3 and WINDOW 4.1 draw solar optical data from the same glazing property libraries. These libraries have been compiled by the group that maintains the WINDOW program using data received from various glazing manufacturers. In most cases spectral optical properties have been obtained for the individual glazings and the band-averaged solar optical properties have been calculated. Equation 9 shows the way in which any given solar optical property, say, $p$, can be determined by averaging the corresponding spectral data, $p(\lambda)$, over the solar wavelength band using the solar spectral irradiance function, $E(\lambda)$, as a weighting function:

$$
p=\frac{\int_{\lambda=0} p(\lambda) E(\lambda) d \lambda}{\int_{\lambda=0} E(\lambda) d \lambda} .
$$

The solar optical data included in the glazing libraries have been calculated using the ASTM E891-87 (ASTM 1987) solar spectral irradiance function. This irradiance function is specified at 121 wavelength values ranging from $\lambda=0.305 \mu \mathrm{m}$ to $\lambda=4.045 \mu \mathrm{m}$ and represents air mass 1.5 . Plots of this function and a discussion can be found in McCluney (1992).

Once optical properties have been determined for each glazing, it is a straightforward task to account for the many reflections and many occurrences of absorption that will exist in any multielement glazing array. The amounts of reflected, transmitted, and absorbed solar radiation within the glazing system can be calculated according to Equations 7.1.1 a through 7.1.2c of Finlayson et al. (1993) or Equations 1 through 3 of Wright and Sullivan (1992), which were drawn from Edwards (1977). The equation set used in WINDOW 4.1 is solved iteratively to within a preset tolerance. Edwards' solution technique allows a closed-form solution to be calculated. These sets of equations do not appear to be similar but they represent identical models (i.e, they conserve energy and describe the same amounts of reflection, transmission, etc., at each glazing). They can be expected to generate virtually identical results and this has been confirmed with test calculations on several simple glazing systems. 


\section{Spectral Selectivity}

VISION3 uses a multilayer accounting technique and band-averaged solar (i.e., total solar) optical properties to determine how much solar energy is absorbed, reflected, and transmitted. WINDOW 4.1 offers the same approach but also offers the option of using the spectral optical data to trace solar radiation in a series of wavelength bands within the solar band. The amounts of energy absorbed, reflected, and transmitted in each band are summed to determine the total fluxes of solar radiation.

Results generated using a spectral calculation will depend on the solar irradiance function used. Depending on the selectivity of the window glazings, different results will be found if, for example, an air-mass 2 irradiance function is used instead of the air-mass 1.5 function. The spectral irradiance function of an artificial source will also generate differences (see McCluney [1992]). Therefore, if a glazing system with spectrally selective glazings is being examined, increased accuracy can be obtained by using the known irradiance function to perform a spectral calculation or as the weighting function in Equation 3 to determine the total solar optical properties. This is important if an attempt is being made to match calculated and measured results-especially if an artificial source is being used.

The difference in solar gain results produced by the multiband and single-band solar optical models can be explored by looking at some examples. $\mathrm{SHGC}_{c g}$ results showed a difference of less than 0.01 in a double-glazed unit with a 3-mm clear glass outdoor glazing plus a similar indoor glazing with a pyrolytic low-e $(\varepsilon=0.197)$ coating. The multiband model predicted $\mathrm{SHGC}_{c g}=0.718$, while the single-band result was $\mathrm{SHGC}_{c g}=0.715$. A similar glazing system with the same low-e coating on $6-\mathrm{mm}$ clear glass and a 6-mm mild-green tinted glazing (solar transmittance = 0.328 ) exhibits a difference of less than 0.01. In this case, the multiband model gave $\mathrm{SHGC}_{c g}=0.335$ versus $\mathrm{SHGC}_{c g}=$ 0.332 from the single-band model. The discrepancy between the two models can be greater in some instances. An example is given in Appendix A of LBL (1992), where a 1/4-in. low-e coated glass is used in conjunction with a $1 / 4$-in. green glass and the multiband model gave a solar gain result that was 0.04 lower than that produced by the single-band model $\left(\mathrm{SHGC}_{c g}=0.29\right.$ vs. $\left.\mathrm{SHGC}_{c g}=0.33\right)-\mathrm{a} 14 \%$ difference.

$\mathrm{SHGC}_{c g}$ values quoted for the first two glazing systems discussed in the previous paragraph were generated using WINDOW 4.1. Almost identical results were produced by a multiband model that was written for VISION4 which has not yet been released. The two programs use the same solar spectrum and spectral glazing data. Very minor differences in calculated $\mathrm{SHGC}_{c g}$ values may arise because VISION4 subdivides each wavelength panel into four subpanels for increased accuracy. The third glazing system discussed above could not be simulated using VISION4 because insufficient data are provided to identify the glazings.

\section{Directional Properties}

The optical libraries used by VISION3 and WINDOW4.1 contain solar optical data that pertain to solar radiation incident normal to the glazing surface. VISION3 can be used to simulate solar radiation incident at off-normal angles if the user provides the appropriate solar optical data for each glazing. WINDOW 4.1 estimates the off-normal solar optical properties using the known property at normal incidence and an approximate method (Finlayson et al. 1993) that is known to be very accurate for uncoated glazings (Furler 1991; Milburn 1994) but is not as accurate for glazings with coatings or surface treatments. No attempt is made by either program to account for interference, polarization, or the effects of directionally selective coatings or glazings.

The change in solar gain as a function of incidence angle was checked using WINDOW 4.1. SHGC $_{c g}$ decreased by less than $1 \%$ when the incidence angle was changed from zero to 30 degrees from normal for conventional single-, double-, and triple-pane glazing systems. When doubleglazed with low-e and double-glazed with low-e and argon glazing systems were simulated, the corresponding decrease in $\mathrm{SHGC}_{c g}$ was less than $2 \%$. In all cases $\mathrm{SHGC}_{c g}$ decreases sharply at higher incidence angles toward the limit of zero at a 90-degree incidence angle. Very similar observations were made by Carpenter and Baker (1992) on the basis of calculations carried out using VISION2. A graph summarizing their results is shown in Figure 3.

It can be seen that the experimental determination of solar gain should not be carried out with solar radiation at high incidence angles because $\mathrm{SHGC}_{c g}$ will be highly sensitive to the incidence angle, making test conditions and results difficult to reproduce. Furthermore, if the incident radiation is restricted to near-normal incidence angles, the corresponding simulations can be carried out using the readily available solar optical data from existing libraries.

Measured or calculated SHGC values pertaining to normal insolation are useful when comparing various design configurations but will be of limited value for building energy simulation studies. Beam radiation seldom reaches a window at an incidence angle of less than 30 degrees. This is especially true in the southern United States.

WINDOW 4.1 calculations also show that $\mathrm{SHGC}_{c g}$ decreased by $9 \%$ to $16 \%$ when the five glazing systems discussed above were simulated with diffuse irradiation instead of beam radiation at normal incidence. This indicates that difficulty can be expected when trying to reproduce measured SHGC values if the test condition includes both beam and diffuse insolation. Furthermore, it can be seen that SHGC measurements for different windows cannot be legiti- 


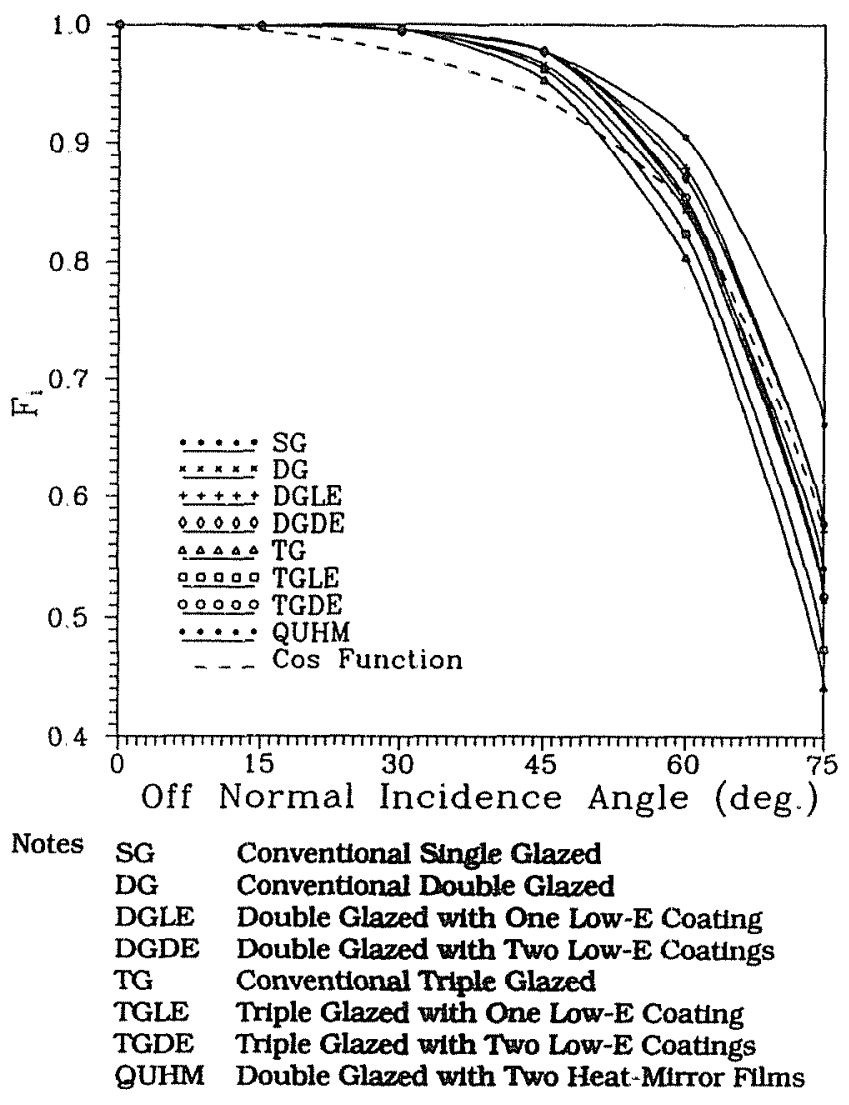

All Low-E Coatings: $\varepsilon=0.09$

Cos Function $=1-A\left[\frac{1}{\cos (B)}-1\right] \begin{aligned} & A=\text { a constant } \\ & B=\text { angle of incidence }\end{aligned}$

Figure $3 \quad S H G C_{c g}$ off-normal incidence correction, $F_{i}$ (reproduced with permission from Carpenter and Baker [1992]).

mately compared unless all tests were carried out with the same ratio of beam and diffuse insolation.

\section{HEAT TRANSFER}

\section{Background}

Center-glass heat flow through a window system composed of parallel glazings or films can be quantified using a relatively simple 1-D analysis of coupled heat transfer. VISION and WINDOW incorporate the same framework within which convective and radiative heat transfer models are combined. This framework provides one feature that sets VISION and WINDOW apart from the more conventional hand calculation methods. Their radiative exchange models are capable of treating glazings that are partially transparent to thermal radiation. This makes it possible to quantify the performance of thin plastic films that could not otherwise be considered (Wright 1985).
The governing equations used to impose energy balances at each of the glazings involve both convective and radiative modes of heat transfer. Therefore, they are nonlinear and cannot be solved in a closed form. Fortunately, they can readily be solved using iterative methods.

Documentation is available regarding the way in which radiative exchange and convective heat transfer models can be solved simultaneously (Wright 1980; Hollands and Wright 1982; Rubin 1982; Arasteh et al. 1989). These references pertain well to the models used in earlier versions of VISION and WINDOW.

The heat transfer models used in VISION3 and WINDOW 4.1 have been extended to account for the thermal resistance of the glazings themselves. WINDOW 4.1 treats each glazing with a center-plane node where it is assumed solar energy is absorbed. Heat transfer between this center node and the glazing surfaces takes place purely by conduction. In contrast, VISION3 considers the two surface temperatures at each glazing. A continuous temperature profile through the glazing is found analytically, assuming that solar energy is absorbed evenly through the thickness of the glazing. It is unlikely that there is any appreciable difference between these two methods or between either of these methods and reality. This is especially true for more conventional glazing systems, where the thermal resistance of the glazings is a small portion of the total thermal resistance, because of the relatively high conductivity of glass used in relatively thin sections. Furthermore, it can be shown that the calculation of the inward-flowing fraction is the same regardless of whether the solar radiation is absorbed evenly through the glazing or at the center-plane.

The radiative exchange model used in VISION and WINDOW was developed from basic principles. The glazing surfaces are treated as infinite parallel planes and the indoor and outdoor facing surfaces are modeled as small surfaces in large enclosures. There is no possibility for differences to exist between these two models. However, the two heat transfer models do differ in other ways. The correlations used to estimate coefficients for convective heat transfer between glazings are empirical and there are several small differences in the way these coefficients are estimated by VISION3 and WINDOW 4.1.

\section{Indoor and Outdoor Convection}

The correlations used for indoor-side and outdoor-side convective heat transfer coefficients are the same in VISION3 and WINDOW 4.1. These correlations represent natural convection on the indoor surface and forced convection on the outdoor surface. Some controversy exists concerning their validity, so it is likely that the discrepancy between the simulation and measured results will be reduced if measured indoor and outdoor convective heat transfer coefficients can be substituted in place of the values generated by correla- 
tions. This effect will be most noticeable in glazing systems that both absorb a significant amount of solar radiation and also have low thermal resistance (e.g., single glazed where the overall thermal resistance of the glazing system is composed almost entirely of the indoor and outdoor thermal resistances).

Uncertainty in estimating the indoor and outdoor convection coefficients leads to less error in calculating solar gain than might first be expected. There are several reasons for this. Very little thermal resistance exists between the outdoor glazing and the outdoor environment because the forced convection heat transfer coefficient is large. Therefore, the outdoor convective coefficient can vary appreciably before the indoor/outdoor thermal resistance distribution of the glazing system is altered enough to change the inwardflowing fraction of absorbed solar radiation.

On the indoor side, more thermal resistance exists but most of the heat transfer between the window and the indoor space takes place by radiation. Again, the inward-flowing fraction will be relatively insensitive to the indoor-side convection coefficient. If the indoor-facing surface has a low-e coating, the inward-flowing fraction would be more sensitive to the indoor convection coefficient, depending on the design of the glazing system in question.

A variety of VISION3 simulation runs were made in order to examine these assertions. VISION3 was modified such that the indoor and outdoor convection coefficients were initially fixed at $h_{c i}=3 \mathrm{~W} / \mathrm{m}^{2} \cdot \mathrm{K}$ and $h_{c o}=23 \mathrm{~W} / \mathrm{m}^{2} \cdot \mathrm{K}$, respectively. Subsequently, two sets of simulation runs were completed - one with $h_{c i}$ increased by $50 \%$ and the other with $h_{c o}$ increased by $50 \%$. The resulting $\mathrm{SHGC}_{c g}$ values are shown in Table 1 for conventional single glazed (SG), conventional double-glazed (DG), double-glazed low-e
(DGLE), double-glazed low-e with argon (DGLEA), plus a tinted single-glazed (SGT) and the same tinted single glazing with the emissivity of the indoor-facing surface reduced to 0.1 (SLET).

Table 1 shows several interesting results. In most cases the difference between SHGC values calculated using the ASHRAE summer and ASHRAE winter weather conditions was too small to be seen in the second significant digit. This suggests that great leeway is available in choosing levels of insolation and temperature difference under which testing can successfully be carried out.

The conventional single-glazed window shows no sensitivity to changes in the indoor or outdoor convection coefficients because the amount of solar radiation absorbed in the glass is small in relation to the amount transmitted, and only a small portion of the amount absorbed is redirected to the indoor space (see Arasteh et al. [1985]).

In contrast, the tinted single-glazed system (SGT) absorbs more than $50 \%$ of the incident solar radiation, making $\mathrm{SHGC}_{c g}$ more sensitive to changes in the indoor and outdoor convection coefficients. However, $50 \%$ increases in these convection coefficients only changed $\mathrm{SHGC}_{c g}$ by about $4 \%$. It is surprising that the reduction of indoor-side emissivity on the tinted single-glazed unit (SLET) increases this sensitivity only moderately.

The solar gain of the double-glazed units was found to be very insensitive to changes in the indoor/outdoor convection coefficients. Carpenter and Baker (1992) also show that the solar gain of untinted windows is very insensitive to wind speed (outdoor convection coefficient). This result is encouraging because it suggests that inordinate effort and expense need not be devoted to tailoring highly repeatable convection coefficients in a solar gains test apparatus.
TABLE 1 SHGC $_{c g}$ vs. Indoor/Outdoor Convection Coefficients

\begin{tabular}{lcccc} 
& $\begin{array}{c}\mathrm{h}_{\mathrm{cl}}= \\
\mathrm{h}_{\mathrm{co}}=\end{array}$ & $\begin{array}{c}3.0 \\
23.0 \\
\mathrm{~W} / \mathrm{m}^{2} \mathrm{~K}\end{array}$ & $\begin{array}{c}4.5 \\
23.0 \\
\mathrm{~W} / \mathrm{m}^{2} \mathrm{~K}\end{array}$ & $\begin{array}{c}3.0 \\
\mathrm{~W} / \mathrm{m}^{2} \mathrm{~K}\end{array}$ \\
SG & $0.86 / 0.86$ & $0.86 / 0.86$ & $0.85 / 0.85$ \\
DG & $0.76 / 0.76$ & $0.76 / 0.77$ & $0.76 / 0.76$ \\
DGLE & $0.64 / 0.64$ & $0.65 / 0.64$ & $0.64 / 0.64$ \\
DGLEA & $0.65 / 0.64$ & $0.55 / 0.65$ & $0.64 / 0.64$ \\
SGT & $0.48 / 0.47$ & $0.50 / 0.49$ & $0.45 / 0.44$ \\
SLET & $0.41 / 0.41$ & $0.43 / 0.44$ & $0.39 / 0.39$ \\
\hline SHGC & & & \\
\hline Cg & & & \\
\hline
\end{tabular}

\section{Natural Convection Between Glazings}

The coefficient for convective heat transfer between adjacent glazings, $h$, can be expressed in terms of the dimensionless Nusselt number $(\mathrm{Nu})$, the fill-gas conductivity $\left(k_{f g}\right)$, and the thickness of the gas layer $\left(t_{f g}\right)$ :

$$
h=\mathrm{Nu} \frac{k_{f g}}{t_{f g}} .
$$

When convection is unimportant, $\mathrm{Nu}$ is equal to one and $h$ is quantified as though heat transfer is taking place purely by conduction. As convection augments the heat transfer, $\mathrm{Nu}$ increases. $\mathrm{Nu}$ can be calculated as a function of the gas-layer Rayleigh number (Ra) and the cavity height-to-width aspect ratio $(A)$. It has been found that in vertical cavities $\mathrm{Nu}$ is not a function of $A$ unless $A$ is less than 25. It is unusual for $A$ to be less than 25 in window applications. Therefore, it is Ra that 
is of greatest importance in determining $h$. Ra is a function of gas properties, gas-layer thickness, and temperature difference across the gas layer, $\Delta T$ :

$$
\mathrm{Ra}=\frac{\rho^{2} t_{g}^{3} g C_{p} \Delta T}{\mu k_{g} T_{m}} .
$$

$T_{m}$ is the mean temperature of the gas layer and $g$ is the acceleration due to gravity. VISION3 calculates the gas density, $\rho$, using the ideal gas law assuming that the pressure in the cavity is one atmosphere. WINDOW 4.1 performs a similar calculation but uses a linear curve fit based on measured data instead of the ideal gas law. (The curve fit for the density of argon included in versions of WINDOW prior to version 4.0 included a typographical error. Therefore, the Ufactors from simulations of argon-filled windows using WINDOW 4.0 or 4.1 differ slightly from results of WINDOW 3.1.) Both programs calculate the remaining gas properties (specific heat, $C_{p}$; viscosity, $\mu$; and conductivity) using linear curve fits as a function of $T_{m}$. These curves are based on published data and the two sets generally agree to within a fraction of $1 \%$.

The correlation used by WINDOW 4.1 to calculate $\mathrm{Nu}$ as a function of $\mathrm{Ra}$ for vertical cavities is taken from ElSherbiny et al. (1982) and is based on experiments done at a Canadian university. ElSherbiny provides a "design correlation" that does not include aspect ratio dependence for $A>$ 25 plus correlations meant to closely reproduce the detail of experimental data at several fixed aspect ratios. WINDOW 4.1 incorporates the correlation that applies to the $A=40$ data. The design correlation of ElSherbiny was used in earlier versions of VISION but has been replaced in VISION3 by a correlation by Wright (1991) that was developed more specifically for window applications based on the data of ElSherbiny and additional experimental data from Shewen (1986). It was discovered that EISherbiny's design correlation was flawed in the way its formulation was published. The two Nu/Ra functions used for vertical cavities in WINDOW 4.1 and VISION3 are plotted in Figure 4. Over the range of Ra of most interest for glazing system calculations- $\mathrm{Ra}<12,000$ - these two correlations differ by no more than about $2 \%$.

The Nu/Ra correlations used by WINDOW 4.1 and VISION3 for tilt angles other than vertical are identical. These are based on ElSherbiny et al. (1982), Hollands et al. (1976), and Arnold et al. (1974). However, for tilt angles between 60 degrees (a skylight 30 degrees from vertical) and 180 degrees (a window facing straight down), the value of $\mathrm{Nu}$ calculated by the two programs will still differ slightly (less than $2 \%$ ) because these correlations are formulated in terms of the value of $\mathrm{Nu}$ in a vertical cavity.

Table 1 also holds an important piece of information about convective heat transfer in glazing cavities. Examine the $\mathrm{SHGC}_{c g}$ values for the DGLE and the DGLEA glazing systems. These glazing systems both consist of double glazing with a low-e coating on surface 3 so most of the heat transfer between the glazings takes place by convection. The DGLEA unit has argon fill gas instead of air. This difference in fill gas makes a significant difference in the convective heat transfer coefficient between the glazings-primarily because the conductivity of argon is only about two-thirds the conductivity of air (see Equation 10). The interpane convection heat transfer coefficient in the argon-filled unit is at least $25 \%$ lower than in the air-filled unit but the solar gain of the two units is almost identical. This is noteworthy. If a change that alters the interpane convection coefficient by $25 \%$ has little bearing on $\mathrm{SHGC}_{c g}$ then much smaller uncertainties or variations in other quantities will certainly be unimportant. Examples of such quantities and their approximate uncertainties include fill-gas properties ( $0.5 \%$ in curve fit), Nusselt number (up to $5 \%$ in correlation), component fraction in fill-gas mixtures ( $10 \%$ uncertainty in mole fractions yielding up to $2 \%$ uncertainty in gas properties), and pane spacing ( $3 \%$ due to moderate pane deflection).

It can be seen why the solar gain of a glazing system is not sensitive to changes in interpane convection. If the thermal resistance between two glazings is increased, a larger portion of the solar energy absorbed at glazings between that cavity and the indoor side will flow to the indoor space. However, a smaller portion of the solar energy absorbed at glazings between that cavity and the outdoor side will reach the conditioned space. These two changes in solar gain will always cancel to some extent.

SHGC $_{c g}$ will be more sensitive to changes in the interpane convection coefficient if solar energy is absorbed more heavily on one side of the glazing cavity than the other. This is the case with the DGLE and DGLEA glazing systems listed in Table 1. The glazing with the low-e coating absorbs about three times as much solar energy as the outdoor-side glazing made of uncoated clear glass. A more extreme imbalance exists in the glazing system shown in Figure 2, where the indoor glazing is heavily tinted. If the fill gas in this glazing system is changed from air to argon, the calcu-

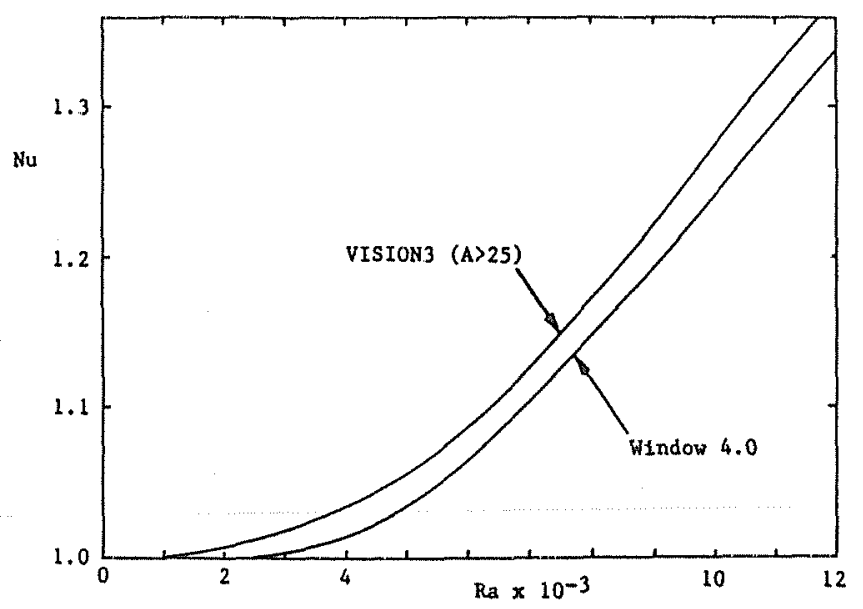

Figure 4 Correlations used to calculate convective heat transfer coefficients between vertical glazings. 
lated $\mathrm{SHGC}_{c g}$ value changes from 0.62 to 0.63 . Even if the radiative exchange between the two glazings is suppressed by lowering the emissivity of one of the surfaces to 0.1 (without changing any solar optical properties), the change in fill gas from air to argon only changes the SHGC from 0.70 to 0.72 . Even in this extreme situation the solar gain is not very sensitive to the interpane convection coefficient.

\section{Weather Conditions}

Having seen that solar heat gain is not sensitive to variations in the interpane convection coefficient, it is instructive to examine the effect of the two weather conditions used to produce the results of Table 1 . The ASHRAE weather conditions are tabulated on page 21 of Wright and Sullivan (1992). The summer condition includes a moderate indoor/ outdoor temperature difference with a higher outdoor temperature plus a high level of insolation. The winter condition includes a much lower outdoor temperature and no insolation (see page 24 of Wright and Sullivan [1992] to see how SHGC can be calculated even when no solar radiation is present). The solar optical properties of the glazing system are not affected by changes in temperature or insolation level, so the different weather conditions do not change the portions of incident solar radiation absorbed at the various glazings or directly transmitted to the indoor space. The only way that the different weather conditions change solar gain is by changing the temperature distribution through the glazing system, which, in turn, changes the heat transfer coefficients that govern the rates of heat transfer within the glazing system.

Figures 5 and 6 show VISION3 output plots for the DGLE glazing system simulated under the ASHRAE winter and summer conditions, respectively. Again the indoor and outdoor convective heat transfer coefficients have been fixed at 3.0 and $23.0 \mathrm{~W} / \mathrm{m}^{2}{ }^{\circ} \mathrm{C}$. Examine the gap between the glazings. Under the winter conditions the temperature drop across the cavity is large, with $\mathrm{Ra}=8,153$ and $\mathrm{Nu}=1.17$. Under the summer conditions the temperature drop is small, with $\mathrm{Ra}=139$ and $\mathrm{Nu}=1.00$.

The $17 \%$ increase in the convective heat transfer coefficient is offset somewhat by a decrease in the radiative heat transfer coefficient. It can be shown that the radiative coefficient will vary approximately with $T_{m}^{3}$. In this case $T_{m}$ decreases by about $11 \%$ from the summer to the winter conditions and the radiative coefficient decreases by almost $40 \%$. However, the radiative coefficient is much smaller than the convective coefficient because a low-e coating is present and the change in the heat transfer coefficient between the two glazings due to the combined effect is an increase of $8 \%$.

An argument could be made that the solar gain of the standard double-glazing system (DG) might be sensitive to the change in weather conditions because the interpane heat transfer is dominated by radiative exchange. Table 1 shows that this is not true. In this case, the switch from summer to winter weather and the corresponding change from low $\Delta T$ and high $T_{m}$ to high $\Delta T$ and low $T_{m}$ results in an increase in $\mathrm{Nu}$ of $10 \%$, a decrease in the radiative coefficient of $31 \%$, and a net decrease in the heat transfer coefficient of $21 \%$. Again, this is not sufficient to appreciably change $\mathrm{SHGC}_{c g}$,

The combination of low $\Delta T$ and high $T_{m}$ or high $\Delta T$ and low $T_{m}$ tends to create offsetting changes in the interpane heat transfer components. This phenomenon can also be expected in glazing systems with more than two glazings. Assuming that the indoor-side temperature is always held at some temperature near $21^{\circ} \mathrm{C}$, the only weather condition that would cause a cavity to experience high $\Delta T$ and high $T_{m}$ would involve either a very high outdoor temperature or a very badly overheated intermediate glazing. Carpenter and Baker (1992) also show that the SHGC of a double-glazed low-e window is very insensitive to outdoor temperature and insolation level.

\section{Clear Sky Conditions}

Less thermal radiation comes from sections of clear sky than from objects in the outdoor environment that exist with temperatures at or near the outdoor air temperature. Therefore, the outdoor glazing of a window exposed to clear sky conditions will be cooled by radiant exchange. This results in a lower solar gain but the effect is not expected to be strong because heat transfer to the outdoor environment is usually dominated by convection.

The effect of clear sky cooling is illustrated in Figures 7 and 8 , which show results for the DGLEA glazing system. Figure 7 shows the results of simulation under the ASHRAE summer condition. The weather conditions used to generate the results of Figure 8 are identical, with the exception that the cloud cover has been reduced from $100 \%$ to zero. The dashed line shown on the outdoor side in Figure 8 represents radiant heat transfer between the outdoor glazing and the environment.

VISION3 and WINDOW 4.1 include radiant exchange models that can account for clear sky conditions. The clear sky effect is incorporated by modeling the clear sky portion of the environment with an emissivity of less than one. Identical equations for calculating clear sky emissivity can be found in Wright and Sullivan (1992) and Arasteh et al. (1989). However, WINDOW 4.1 does not implement the sky emissivity model. Instead, the sky emissivity or sky temperature can be altered manually but no guidance is given about the appropriate values to enter.

VISION3 was used (without its indoor and outdoor convection coefficients artificially fixed) to simulate the glazing systems listed in Table 1. Two weather conditions were used-the ASHRAE summer condition and the same condition with zero cloud cover. Removal of the cloud cover reduced the $\mathrm{SHGC}_{c g}$ from 0.86 to 0.85 for the single-glazed system (SG) and from 0.52 to 0.51 for the tinted single- 

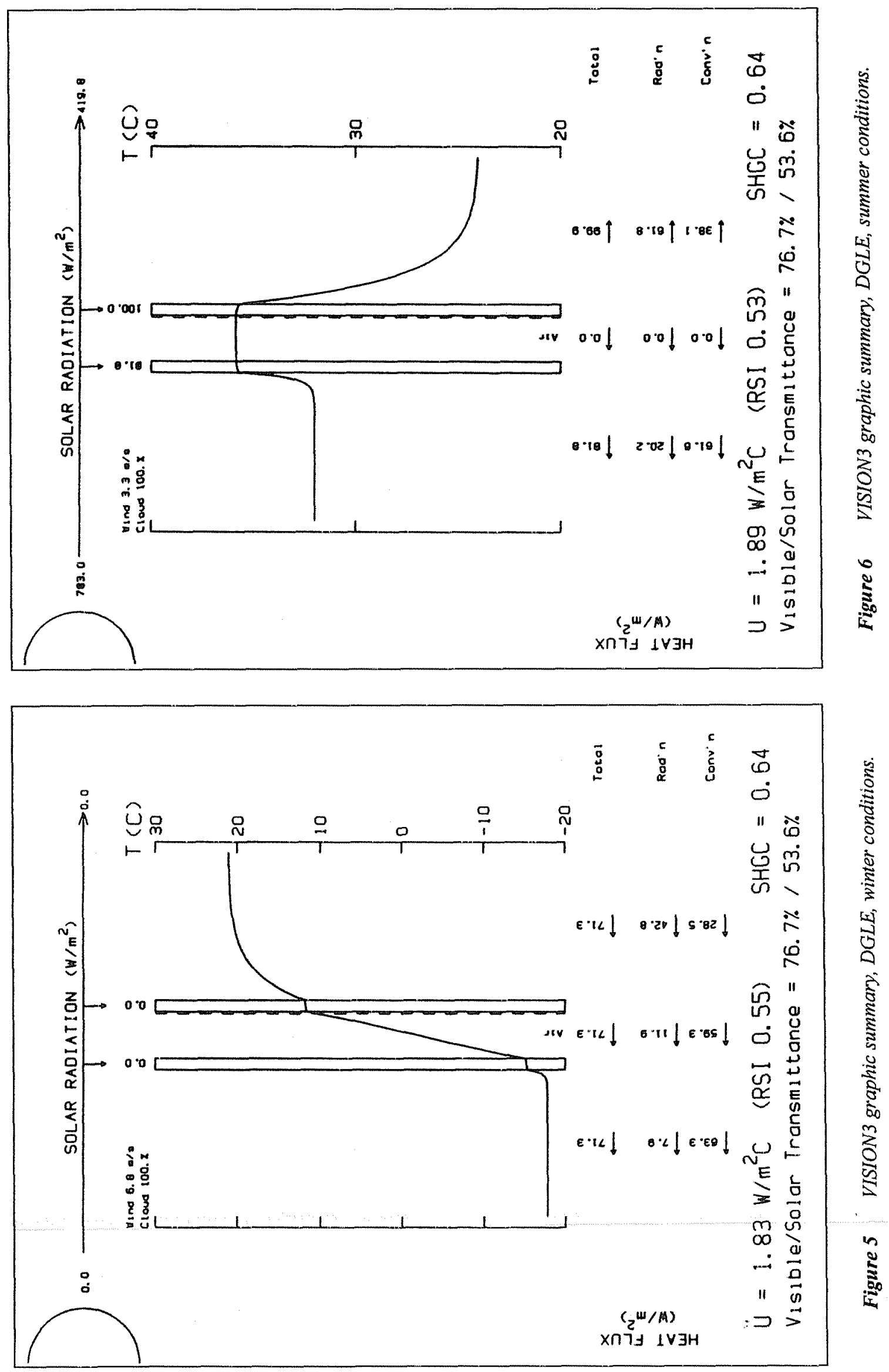

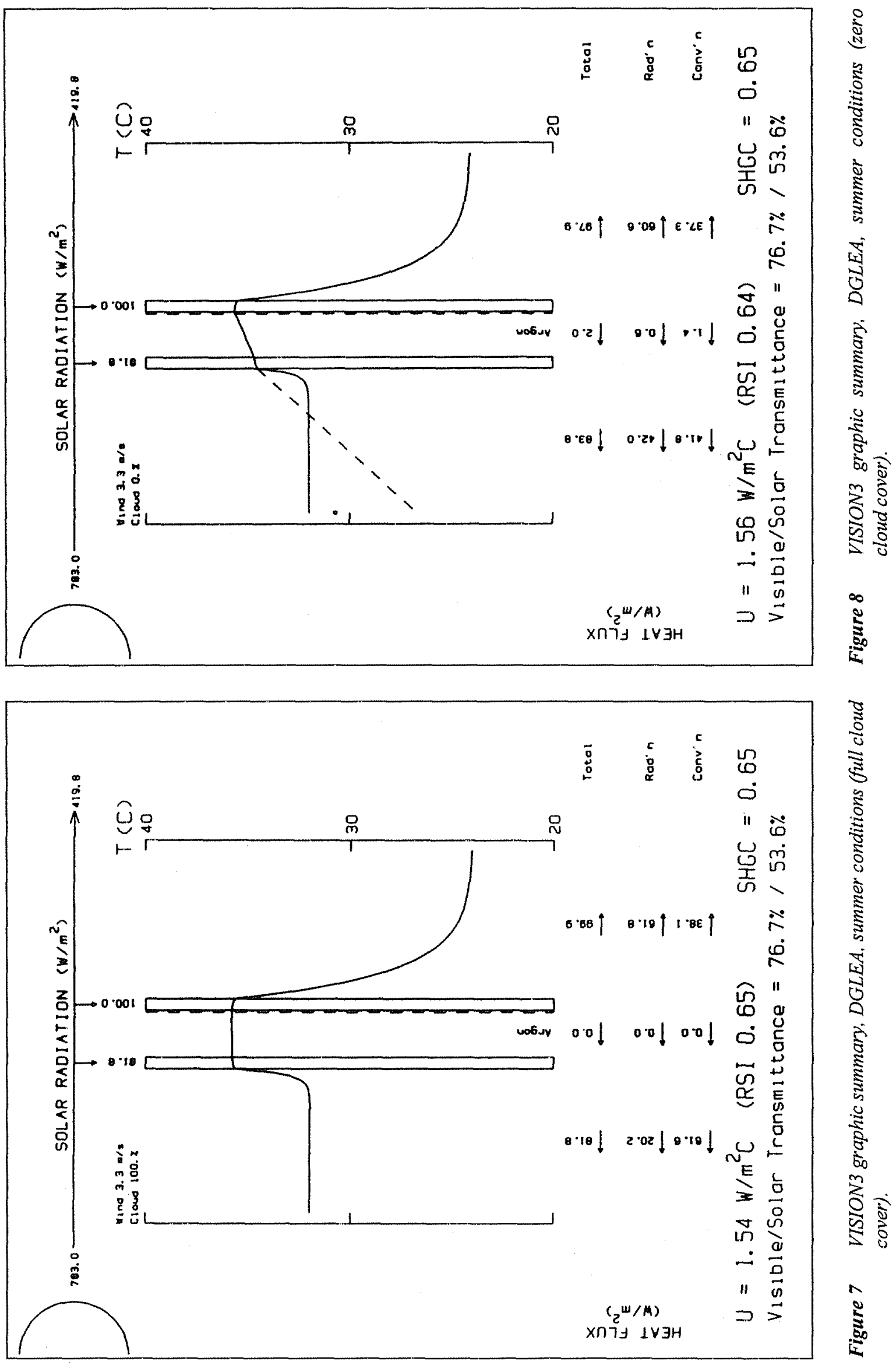
glazed system (SGT). All other $\mathrm{SHGC}_{c g}$ results did not change with cloud cover. These results indicate that outdoor solar heat gain test results will not be appreciably affected by changes in radiant exchange between the window and its environment because of changes in cloud cover.

\section{SENSITIVITY TO DESIGN AND OPERATING PARAMETERS}

\section{Glazing System Description}

The previous sections of this study have dealt with descriptions and comparisons of the solar heat gain models found in VISION3 and WINDOW 4.1. This section examines the sensitivity of solar heat gain with respect to the various input parameters needed to describe a glazing system for purposes of simulation. The input requirements of VISION3 and WINDOW 4.1 are identical, with the exception that spectral optical data may be used by WINDOW 4.1 for greater accuracy. It is beyond the scope of this paper to examine the effect of changes in individual spectral data. Instead, total optical properties are used in this section. The solar and longwave parameters listed below must be specified for each glazing.

\section{Solar Optics}

$\rho_{f}, \rho_{b}=$ reflectance to solar radiation incident from the outdoor (front) and indoor (back) sides, respectively

$\tau_{s}=$ transmittance to solar radiation

\section{Longwave Optics}

$\varepsilon_{f}, \varepsilon_{b}=$ hemispheric longwave emissivity of the outdoor (front) and indoor (back) sides of the glazing, respectively

$\tau_{L} \quad=$ longwave hemispheric/hemispheric transmittance

\section{Other Quantities}

$t_{g l}=$ glazing thickness

$k_{g l}=$ glazing thermal conductivity

Also quantities include pane spacing, fill gas type $\left(t_{f g}\right)$, and glazing system tilt $(\theta)$.

It was expected that calculation of solar gain would be insensitive to several of these parameters. For example, the solar heat gain is not strongly affected by changes in interpane convection coefficients so it should be insensitive to changes in glazing emissivity, pane spacing, or glazing system slope.

\section{The Jiggle Method}

When an experiment or simulation is used to determine a result, $R$, it is informative to estimate the uncertainty in $R$, say, $\delta R$, arising from uncertainties in the independent variables, $X_{i}$, that determine $R$. The conventional method of tracing the propagation of uncertainty from $n$ independent variables to the uncertainty in $R$ is given by the root-meansquare calculation:

$$
\delta R=\left(\sum_{i=1}^{\mu}\left(\frac{\partial R}{\partial X_{i}} \delta X_{i}\right)^{2}\right)^{1 / 2} .
$$

Sometimes the partial derivatives cannot be evaluated analytically and it is more convenient to estimate these terms numerically. If the input variables are each changed slightly and the size of each perturbation is equal to $\delta X_{i}$, the resulting changes in the analysis output, $\delta R_{i}$, can be used directly to evaluate Equation 12 (Moffat 1985, 1988):

$$
\delta R=\left(\sum_{i=1}^{\text {in }}\left(\delta R_{i}\right)^{2}\right)^{1 / 2} .
$$

In this case the result of interest is $\mathrm{SHGC}_{c g}$, and the $X_{i}$ are the glazing system description parameters, giving

$$
\delta \operatorname{SHGC}_{c g}=\left(\sum_{i=1}^{\sum_{1}}\left(\delta \operatorname{SHGC}_{c g, i}\right)^{2}\right)^{1 / 2} \text {. }
$$

Thus, by "jiggling" the input variables, it is possible to estimate the overall uncertainty in $\mathrm{SHGC}_{c g}$ using a calculation routine such as VISION or WINDOW.

\section{Design Parameters}

VISION3 was used to calculate $\delta \mathrm{SHGC}_{c g}$ results under the ASHRAE winter design condition for the six glazing systems shown in Table 1. Data summarizing this analysis are given in Tables 2 and 3. In each case, optical properties were changed by 0.02 , glass conductivity was changed by $10 \%$, pane spacing was changed by $1 \mathrm{~mm}$, fill-gas composition was changed by $10 \%$, and window tilt was changed from 90 degrees to 80 degrees. Glazing thickness was not altered, as this only duplicates the effect of changing glazing conductivity. The resulting values of $\delta \mathrm{SHGC}_{c g, i}$ were used to calculate $\delta \mathrm{SHGC}_{c g}$ according to Equation 14. If it is felt that any of the $\delta X_{i}$ values are not appropriate, it is possible to scale $\delta \mathrm{SHGC}_{c g, i}$ up or down accordingly and determine a new value of $\delta \mathrm{SHGC}_{c g}$.

\section{Operating Parameters}

Additional VISION3 runs were made to quantify the effect of variations in operating parameters. The independent variables considered were indoor/outdoor film coefficients (radiation and convection combined), outdoor film coefficient, irradiance level, sky condition (i.e., cloud cover), and absorptivity inside the room. Again, the ASHRAE winter design condition was used except when overridden by parameters such as irradiation or sky condition. The results are presented in Table 4 and are provided primarily to supplement discussions already presented.

Table 4 lists values of $\mathrm{SHGC}_{c g}$ for the glazing systems included in Table 1 . It is possible to manually take differences between the listed values and estimated values of $\delta \mathrm{SHGC}_{c g, i}$ and $\delta \mathrm{SHGC}_{c g}$, as was done in Tables 2 and 3. 
TABLE 2

Uncertainty in $\mathrm{SHGC}_{c g}$ for Single-Pane Glazing Systems

\begin{tabular}{|c|c|c|c|c|c|c|c|c|}
\cline { 3 - 9 } \multicolumn{2}{c|}{} & \multicolumn{2}{c|}{ SG } & \multicolumn{2}{c|}{ SGT } & \multicolumn{2}{c|}{ SLET } \\
\hline 1 & $\begin{array}{c}\text { vari- } \\
1\end{array}$ & $\delta \mathrm{X}_{1}$ & $\mathrm{X}_{1}$ & $\delta \mathrm{SHGC}_{\mathrm{cg}, 1}$ & $\mathrm{X}_{1}$ & $\delta \mathrm{SHGC}_{\mathrm{cg}, \mathrm{I}}$ & $\mathrm{X}_{1}$ & $\delta \mathrm{SHGC}_{\mathrm{cg}, 1}$ \\
\hline 2 & $\rho_{\mathrm{b}}$ & 0.02 & 0.075 & -0.005 & 0.048 & -0.004 & 0.048 & -0.003 \\
\hline 3 & $\tau_{\mathrm{s}}$ & 0.02 & 0.837 & 0.015 & 0.326 & 0.016 & 0.326 & 0.017 \\
\hline 4 & $\varepsilon_{\mathrm{f}}$ & 0.02 & 0.84 & 0.000 & 0.84 & 0.000 & 0.84 & 0.000 \\
\hline 5 & $\varepsilon_{\mathrm{b}}$ & 0.02 & 0.84 & 0.000 & 0.84 & 0.002 & 0.1 & 0.002 \\
\hline 6 & $\tau_{\mathrm{L}}$ & 0.02 & 0.0 & 0.000 & 0.0 & -0.001 & 0.0 & 0.002 \\
\hline 7 & $\mathrm{k}_{\mathrm{gl}}(1)$ & 0.1 & 0.9 & 0.000 & 0.9 & -0.001 & 0.9 & -0.001 \\
\hline 8 & $\theta$ & $-10^{\circ}$ & $90^{\circ}$ & 0.000 & $90^{\circ}$ & 0.000 & $90^{\circ}$ & 0.000 \\
\hline
\end{tabular}

(1) $\mathrm{W} / \mathrm{m} \cdot \mathrm{K}$

\section{DISCUSSION}

The results shown in Tables 2 and 3 provide several interesting observations. The assumed uncertainties, $\delta X_{i}$, lead to an uncertainty in SHGC of slightly less than 0.02 in all six cases. Additional glazings increase $\delta \mathrm{SHGC}_{c g}$ because more independent variables contribute uncertainties to the total uncertainty. However, this increase is relatively small. The values of $\delta \mathrm{SHGC}_{c g}$ for triple- and quadruple-glazed systems should only be slightly greater than 0.02 .

The most important group of independent variables is the set of solar optical properties. The most important of the solar properties is the solar transmittance and, in particular, the solar transmittance of the outdoor glazing if more than one glazing is present. This difference (between the indoor and outdoor glazing) arises because solar energy that is allowed to pass by the outdoor glazing would have been absorbed otherwise and largely lost to the outdoor environment. In contrast, solar energy passed by the indoor glazing would otherwise have been absorbed and largely redirected to the indoor space.

The solar reflectances of the glazing surfaces also play important roles in determining solar gain but usually to a smaller degree than the glazing transmissivity. The importance of solar reflectance also varies depending on the location of the surface in question. For example, an increase in the solar reflectance of the outdoor-facing surface will always reduce solar gain. However, the solar reflectance of the indoor-facing surface has no influence on solar gain because the models in VISION3 and WINDOW 4.1 assume that none of the solar radiation transmitted to the indoor space is reflected back to the window. This highlights the importance of constructing a test apparatus so that all (or essentially all) transmitted solar radiation is absorbed within the metering enclosure. This is essential to ensure an equitable comparison of one glazing system against the next and to reduce discrepancies between test and simulation results.

It may be difficult to interpret the results opposite the solar optical reflectance properties shown for double glazings in Table 3 . If the surfaces are numbered starting at the outdoor surface, it appears that the solar gain is reduced much more drastically when the solar reflectance of surface 3 is in. creased than when the solar reflectance of surface 1 is increased. This runs contrary to intuition. Remember that the reflectance cannot be varied in a completely independent manner. If the reflectance is increased while holding the transmittance constant, then the absorptance must be decreased. In the case of the indoor glazing, this decrease in absorptance directly decreases the solar gain by reducing the amount of solar energy absorbed-most of which would have been redirected to the indoor space. Increasing the reflectance at the outdoor glazing also reduces the amount of solar energy absorbed, but in this location most of the energy would have been lost to the outdoor environment.

The solar gain of each of the six glazing systems is very insensitive to the variables that govern heat transfer (pane spacing, tilt, fill gas, emissivity, etc.). The change in SHGC $_{c g}$ caused by a change in one of the heat transfer vari. ables was usually zero and was at most 0.002 . This situation was expected on the basis of previous discussions.

The $\mathrm{SHGC}_{c g}$ values listed in Table 4 show that the solar gain of a window can be significantly altered by some operating parameters. An increase in the indoor film coefficient will increase the solar gain. Similarly, a decrease in the outdoor film coefficient can cause the solar gain to increase. A large change in the level of solar radiation $\left(0\right.$ to $\left.1000 \mathrm{~W} / \mathrm{m}^{2}\right)$ caused little change in the $\mathrm{SHGC}_{c g}$. The fractional cloud cover could also be varied over its full range with little effect. In contrast, a small change in the solar absorptivity of the room (1.0 to 0.8$)$ caused a significant change in solar gain. In each case, the largest sensitivity to operating parameters was present in single-glazed windows with tinted glazings. This highlights the idea that film coefficients need to be 
TABLE 3

Uncertainty in $\mathrm{SHGC}_{c g}$ for Double-Pane Glazing Systems

\begin{tabular}{|c|c|c|c|c|c|c|c|c|}
\hline \multirow[b]{2}{*}{$\begin{array}{c}1 \\
(4)\end{array}$} & \multirow[b]{2}{*}{$\begin{array}{l}\text { Vari- } \\
\text { able }\end{array}$} & \multirow[b]{2}{*}{$\delta x_{1}$} & \multicolumn{2}{|r|}{ DG } & \multicolumn{2}{|c|}{ DGLE } & \multicolumn{2}{|c|}{ DGLEA } \\
\hline & & & $x_{1}$ & $\underset{1}{\delta S H G C}$ & $x_{1}$ & $\delta \mathrm{SHGC}_{\mathrm{cg}, 1}$ & $x_{1}$ & $\delta \mathrm{SHGC}_{\text {eg.1 }}$ \\
\hline 1 & $\rho_{f}$ & 0.02 & 0.075 & -0.010 & 0.022 & -0.012 & 0.022 & 0.013 \\
\hline 2 & $\rho_{b}$ & 0.02 & 0.075 & 0.000 & 0.019 & 0.000 & 0.019 & 0.000 \\
\hline 3 & $\tau_{0}$ & 0.02 & 0.837 & 0.006 & 0.63 & 0.004 & 0.63 & 0.003 \\
\hline 4 & $\varepsilon_{f}$ & 0.02 & 0.84 & -0.001 & 0.10 & 0.000 & 0.1 & -0.001 \\
\hline 5 & $\varepsilon_{\mathrm{p}}$ & 0.02 & 0.84 & 0.000 & 0.84 & 0.000 & 0.84 & 0.000 \\
\hline 6 & $\tau_{L}$ & 0.02 & 0.0 & 0.000 & 0.0 & 0.001 & 0.0 & 0.000 \\
\hline 7 & $\rho_{f}$ & 0,02 & 0.075 & -0.003 & 0.075 & -0.001 & 0.075 & -0.002 \\
\hline 8 & $\rho_{b}$ & 0.02 & 0.075 & 0.001 & 0.075 & 0.003 & 0.075 & 0.002 \\
\hline 9 & $\tau_{\mathrm{s}}$ & 0.02 & 0.837 & 0.015 & 0.837 & 0.014 & 0.837 & 0.013 \\
\hline 10 & $\overrightarrow{\varepsilon_{f}}$ & 0.02 & 0.84 & -0.001 & 0.84 & 0.000 & 0.84 & 0.000 \\
\hline 11 & $\varepsilon_{\mathrm{b}}$ & 0.02 & 0.84 & -0.001 & 0.84 & 0.000 & 0.84 & 0.000 \\
\hline 12 & $\tau_{L}$ & 0.02 & 0.0 & -0.001 & 0.0 & 0.000 & 0.0 & 0.000 \\
\hline 13 & $\mathrm{k}_{\mathrm{gl}}{ }^{(1)}$ & 0.1 & 0.9 & 0.000 & 0.9 & 0.000 & 0.9 & 0.000 \\
\hline 14 & $\mathrm{~kg}_{\mathrm{gg}}(1)$ & 0.1 & 0.9 & -0.001 & 0.9 & 0.000 & 0.9 & 0.000 \\
\hline 15 & $t_{\text {fgg }}^{(2)}$ & 1.0 & 12.7 & 0.000 & 12.7 & 0.000 & 12.7 & -0.001 \\
\hline 16 & $\begin{array}{l}\text { fill } \\
\text { gas }\end{array}$ & $\begin{array}{l}\text { air/ar } \\
90 / 10 \\
\end{array}$ & air & 0.000 & air & 0.000 & $\begin{array}{c}\text { argon } \\
\text { (3) }\end{array}$ & -0.001 \\
\hline 17 & $\theta$ & $-10^{\circ}$ & $90^{\circ}$ & 0.000 & $90^{\circ}$ & 0.000 & $90^{\circ}$ & 0.000 \\
\hline & & & $\delta \mathrm{SH}$ & $g=0.019$ & $\delta s$ & $\mathrm{cg}=0.019$ & $\delta s$ & $C_{c g}=0.019$ \\
\hline
\end{tabular}

(1) $\mathrm{W} / \mathrm{m} \cdot \mathrm{K}$

(2) $\mathrm{mm}$

(3) changed to air $/ a r=10 / 90$

(4) 1-6 and 13 - indoor glazing/7-12 and 14 - outdoor glazing mate the solar heat gain of the frame. $\mathrm{SHGC}_{f r}$ may even be neglected if the frame is not thermally unbroken aluminum.

When calculating solar gain, the most important concern is to accurately determine the amounts of solar radiation directly transmitted to the indoor space and absorbed in the glazing system. The solar optical models used to determine these quantities for glazing systems with planar, parallel glazings are simple and straightforward. Models that incorporate a spectral calculation are consistently more accurate. The accuracy of any solar optical model depends primarily on the quality of the optical data available. Therefore, the importance of accurate solar optical measurement techniques must be emphasized.

The existing heat transfer models have been shown to be suitable for calculating the inward-flowing fraction of absorbed solar radiation. In many ways the inward-flowing fraction is very insensitive to the details of the heat transfer models. This indicates that the solar gain of glazing systems containing nonstandard layers (e.g., venetian blinds) may be accurately calculated using a crude heat transfer model as long as the solar optical characteristics are well known. This possibility merits further study.

well known when single-glazed windows are tested and any test apparatus should absorb as much solar radiation as possible within the metering enclosure.

\section{CONCLUSIONS}

Most of the models incorporated in VISION3 and WINDOW 4.1 are identical. The solar optical models differ in that WINDOW offers optional spectral and directional calculations. The heat transfer models differ only because of the different correlations used to determine convective heat transfer coefficients between glazings ${ }^{3}$ and because of very minor differences in fill-gas properties. The calculation of solar heat gain has been shown to be very insensitive to these aspects of the heat transfer models.

Simulations using a 2-D numerical analysis have also shown that it is valid to apply center-glass SHGC results to the full view area of the window. Methods exist to approxi-

\footnotetext{
${ }^{3}$ These are expected to be consistent in the next release of the programs.
}

It is more difficult to quantify solar gain for single glazings than for any of the glazing systems with higher thermal resistance. The inward-flowing fraction of the single glazing can be influenced appreciably by changes in the indoor and outdoor convection coefficients. This effect leads to little uncertainty when dealing with a single clear glazing because most of the solar gain comes from direct transmission, but a single tinted glazing presents greater difficulty. However, this variability of solar gain for the single glazing does not result from modeling difficulties. The solar gain can be expected to fluctuate under real conditions as the convection conditions change at the window surfaces. These conditions will have to be precisely specified for any solar gain test method used to evaluate tinted single glazing. Convection conditions will not need to be so carefully controlled for double-glazed systems or any system with higher thermal resistance.

Many of the conclusions reached through examination of simulation models have been verified by examining the sensitivity of solar gain with respect to the glazing system 
TABLE 4

$\mathrm{SHGC}_{c g}$ as a Function of Various Operating Parameters

\begin{tabular}{|c|c|c|c|c|c|c|}
\cline { 3 - 7 } \multicolumn{1}{c|}{} & $\begin{array}{c}\text { Indoor } \\
\text { Flm } \\
\text { Coefficient }\end{array}$ & $\begin{array}{c}\text { Outdoor } \\
\text { Fllm } \\
\text { Coefficient }\end{array}$ & $\begin{array}{c}\text { Solar } \\
\text { Irrad- } \\
\text { iance }\end{array}$ & $\begin{array}{c}\text { Cloud } \\
\text { Cover }\end{array}$ & $\begin{array}{c}\text { Room } \\
\text { Absorptiv- } \\
\text { ity (\%) }\end{array}$ \\
\cline { 2 - 7 } & $\begin{array}{c}\text { Base } \\
\text { Case } \\
\text { (1) }\end{array}$ & $\begin{array}{c}5 / 10 \\
\left(\mathrm{~W} / \mathrm{m}^{2} \cdot \mathrm{K}\right)\end{array}$ & $\begin{array}{c}10 / 20 / 30 \\
\left(\mathrm{~W} / \mathrm{m}^{2} \cdot \mathrm{K} /\right.\end{array}$ & $\begin{array}{c}200 / 500 / \\
1000 \\
\left(\mathrm{~W} / \mathrm{m}^{2}\right)\end{array}$ & $\begin{array}{c}90 / 50 / \\
0 \\
(\%)\end{array}$ & $\begin{array}{c}0.95 / \\
0.85 / 0.80\end{array}$ \\
\hline SG & 0.857 & $0.850 /$ & $0.877 /$ & $0.857 /$ & $0.857 /$ & $0.819 /$ \\
& & 0.860 & $\begin{array}{c}0.863 / \\
0.857\end{array}$ & $\begin{array}{c}0.857 / \\
0.857\end{array}$ & $\begin{array}{c}0.856 / \\
0.855\end{array}$ & $\begin{array}{c}0.742 / \\
0.703\end{array}$ \\
\hline DG & 0.762 & $0.752 /$ & $0.778 /$ & $0.761 /$ & $0.761 /$ & $0.733 /$ \\
& & 0.766 & $0.766 /$ & $0.761 /$ & $0.760 /$ & $0.675 /$ \\
& & 0.761 & 0.760 & 0.759 & 0.645 \\
\hline DGLE & 0.640 & $0.629 /$ & $0.654 /$ & $0.639 /$ & $0.640 /$ & $0.623 /$ \\
& & 0.646 & $0.644 /$ & $0.637 /$ & $0.638 /$ & $0.587 /$ \\
& & 0.640 & 0.638 & 0.637 & 0.569 \\
\hline DGLEA & 0.644 & $0.634 /$ & $0.655 /$ & $0.643 /$ & $0.643 /$ & $0.627 /$ \\
& & 0.649 & $0.646 /$ & $0.640 /$ & $0.642 /$ & $0.591 /$ \\
& & 0.643 & 0.643 & 0.641 & 0.573 \\
\hline SGT & 0.476 & $0.428 /$ & $0.608 /$ & $0.475 /$ & $0.475 /$ & $0.463 /$ \\
& & 0.498 & $0.517 /$ & $0.474 /$ & $0.470 /$ & $0.437 /$ \\
& & & 0.473 & 0.469 & 0.464 & 0.424 \\
\hline SLET & 0.423 & $0.428 /$ & $0.524 /$ & $0.421 /$ & $0.421 /$ & $0.409 /$ \\
& & 0.498 & $0.452 /$ & $0.417 /$ & $0.416 /$ & $0.381 /$ \\
& $(3)$ & 0.421 & 0.407 & 0.410 & 0.367 \\
\hline
\end{tabular}

(1) ASHRAE winter design condition

(2) Radiation and convection combined

(3) The effect of the low-e coating has been overridden by the fixed fllm coefficient.

design parameters. The uncertainty in calculating $\mathrm{SHGC}_{c g}$ is about 0.02 . Uncertainty in $\mathrm{SHGC}_{c g}$ due to product variability can exceed this level. Again, the parameters affecting heat transfer were of little or no importance and the solar gain was primarily sensitive to the solar optical characteristics of the glazing system. The most important solar optical property is the solar transmittance-particularly the solar transmittance of the outdoor glazing. Solar heat gain is also affected to different degrees by the various solar reflectances within the glazing system.

\section{ACKNOWLEDGMENTS}

This research was supported by ASHRAE technical committee TC-4.5 (Fenestration) under technical research project 713-TRP.

\section{REFERENCES}

Arasteh, D., S. Selkowitz, and J. Hartmann. 1985. Detailed thermal performance data on conventional and highly insulating window systems. Proc. ASHRAE/DOE/BTECC Conference, Thermal Performance of the Exterior Envelopes of Buildings III, Clearwater Beach, FL. Atlanta: American Society of Heating, Refrigerating and AirConditioning Engineers, Inc.

Arasteh, D., S. Reilly, and M. Rubin. 1989. A versatile procedure for calculating heat transfer through windows. ASHRAE Transactions 95(2).

Arnold, J.N., P.N. Bonaparte, I. Catton, and D.K. Edwards. 1974. Experimental investigation of natural convection in a finite rectangular region inclined at various angles from 0 to $180^{\circ}$. Proc. 1974 Heat Transfer and Fluid Mechanics Institute, Corvallis, OR. Stanford, CA: Stanford University Press.

ASTM. 1987. ASTM E891-87, Standard tables for terrestrial direct normal solar spectral irradiance for air mass 1.5. Philadelphia: American Society for Testing and Materials.

Carpenter, S.C., and J.A. Baker. 1992. Determination of total window solar heat gain coefficient. ASHRAE Transactions 98(1).

Edwards, D. 1977. Solar absorption by each element in an absorbercoverglass array. Technical Note. Solar Energy 19: 401402.

EEL. 1989. FRAME: A finite difference computer program to evaluate thermal performance of window frame systems, version 2.0. Waterloo, ON: Enermodal Engineering Ltd.

ElSherbiny, S.M., G.D. Raithby, and K.G.T. Hollands. 1982. Heat transfer by natural convection across vertical and inclined air layers. Journal of Heat Transfer 104: 96102.

Finlayson, E.U., D.K. Arasteh, C. Huizenga, M.D. Rubin, and M.S. Reilly. 1993. WINDOW 4.0: Documentation of calculation procedures. Berkeley, CA: Energy and Environment Division, Lawrence Berkeley Laboratory.

Furler, R.A. 1991. Angular dependence of optical properties of homogeneous glasses. ASHRAE Transactions 97(2).

Hollands, K.G.T., and J.L. Wright. 1982. Heat loss coefficients and effective $\alpha \tau$ products for flat plate collectors with diathermanous covers. Solar Energy 30(3): 211216. 
Hollands, K.G.T., T.E. Unny, G.D. Raithby, and C. Konicek. 1976. Free convection heat transfer across inclined air layers. Journal of Heat Transfer 98: 189-193.

LBL. 1992. WINDOW 4.0: Program description. Publication LBL-32091, UC-350. Berkeley, CA: Lawrence Berkeley Laboratory.

McCluney, R. 1992. The impact of changing source spectra on the solar optical and solar gain properties of window glazings. Report prepared for Queen's University at Kingston under ASHRAE research project RP-713 and ASHRAE TC 4.5 (Fenestration).

Milburn, D. 1994. Measurement of solar transmittance of advanced glazing materials. Ph.D. thesis, Department of Mechanical Engineering. Waterloo, ON: University of Waterloo.

Moffat, R.J. 1985. Using uncertainty analysis in the planning of an experiment. Journal of Fluids Engineering 107.

Moffat, R.J. 1988. Describing the uncertainties in experimental results. Experimental Thermal and Fluid Science $1: 3-17$.

Rubin, M. 1982. Calculating heat transfer through windows. Energy Research 6: 341-349.
Shewen, E.C. 1986. A Peltier effect technique for natural convection heat flux measurement applied to the rectangular open cavity. Ph.D. thesis, Dept. of Mechanical Engineering. Waterloo, ON: University of Waterloo.

Wright, J.L. 1980. Free convection in inclined air layers constrained by a v-corrugated Teflon film. M.A.Sc. thesis, Mechanical Engineering Department. Waterloo, ON: University of Waterloo.

Wright, J.L. 1985. The computer simulation of super window glazing systems which incorporate Teflon (FEP) inner glazings. Proc. ISES/SESCI Intersol '85, Montreal, Canada, vol. 1, pp. 267-271.

Wright, J.L. 1991. Correlations for quantifying convective heat transfer between window glazings. Note prepared for ASHRAE Standards Committee SPC 142 (Standard Method for Determining and Expressing the Heat Transfer and Total Optical Properties of Fenestration Products).

Wright, J.L., and H.F. Sullivan. 1992. VISION3 glazing system thermal analysis: Reference manual. Waterloo, $\mathrm{ON}$ : Advanced Glazing System Laboratory, University of Waterloo, Department of Mechanical Engineering.

\section{DISCUSSION}

Joseph Klems, Staff Scientist, Lawrence Berkeley Laboratory, Berkeley, CA: Your treatment of film coefficient sensitivity assumed that the interior and exterior film coefficients vary in the same direction, while a more realistic assumption for summer worst-case conditions would be that the two move in opposite directions (e.g., lower $h_{o}$ because of no wind and high humidity, and higher $h_{i}$ due to radiation). Why did you not consider this case? What effect would it have on your statements about the importance of film coefficient to SHGC?

John L. Wright: This portion of the study was done simply to demonstrate that SHGC is not strongly affected by $h_{c i}$ and $h_{c o}$-except in the case of tinted single glazing. It was well beyond the scope of this undertaking (as indicated by the title of the paper) to examine the idiosyncrasies of particular weather conditions. Very small changes in the film coefficients, in either direction, could have been used to quantify the sensitivities in question but large changes were chosen to illustrate the point more dramatically. In fact, simulation results using lower values of $h_{o}$ are included in Table 4 and show a decrease in SHGC, as expected, but do not contradict the stated conclusions.

Roger Henry, CANMET Canada, Ottawa, ON: In terms of definition and use of SHGC, there arises the question of where to place a glazing system in a wall-toward the inside plane, the outside plane, or somewhere in between?
Has this "edge effect" been evaluated with respect to impact on solar gain through real windows?

Wright: The methods examined here are used only to determine the portion of incident solar radiation that becomes solar gain. Methods exist for quantifying the amount of insolation and the amount of external shading, but I don't know how much the daily or annual solar gain can be expected to change with respect to the placement of the window. Clearly, SHGC will be increased if the window is mounted clear of external shading such as brick or other veneers. Keep in mind that some light-colored trim may reflect solar radiation and increase the solar gain.

Brian Crooks, Design Engineer, Cardinal IG, Minneapolis, MN: I missed the point being made with the plot of correction factor $\left(F_{i}\right)$ versus off-normal incidence angle. What was the point being made? Also, is it not an oversimplification to apply the same correction factor $\left(F_{i}\right)$ to all glazing systems, especially when considering the wide variation of glazings available today (and also considering the accuracy mentioned with spectral calculations)?

Wright: Several points were made regarding off-normal insolation. SHGC is strongly affected by the incidence angle at angles greater than 30 degrees. Test results generated at high incidence angles will be hard to reproduce. SHGC will also be affected by the beam/diffuse split and this should be recognized when outdoor testing is considered. 